\title{
Macrothink
}

\section{Impact of Deceptive Advertising on Women Buying Behavior: A Study on Cosmetics Industry of}

\section{Bangladesh}

\author{
Md. Muzahidul Islam \\ Lecturer, Army Institute of Business Administration, Savar \\ Savar Cantonment, Dhaka - Aricha Hwy, Savar Union 1344, Bangladesh \\ E-mail: muzahidju03@gmail.com
}

Received: September 25, 2021 Accepted: October 18, 2021 Published: October 20, 2021

doi:10.5296/jebi.v8i2.19110 URL: http://dx.doi.org/10.5296/jebi.v8i2.19110

\begin{abstract}
Deceptive advertisements harm consumers by causing them to have false beliefs about the nature of the products being advertised and thereby causing them to make different purchasing decisions than they would have made otherwise. This is particularly evident in the cosmetics industry in Bangladesh where recently, various forms of advertising techniques deceptive in nature are urgently and increasingly adopted to enhance sales figure and to establish a strong market share. In this quantitative research, the study estimates the relationship of women response against deceptive advertising. The researcher has reported the results of a questionnaire survey of 227 women of this industry using convenience sampling from four different areas in Dhaka city. The findings acquired through using basic statistical tools like descriptive analysis, factor analysis and following multiple linear regression model to provide new insights into deceptive advertising. The impact of deceptive advertising on women buying behavior is highly significant across most of the social and health impact variables like affecting lifestyle, stereotype role, social class, several side effects, fail to give promised services, consequences of cosmetics products.
\end{abstract}

Keywords: Buying Behavior, Bangladesh, Cosmetic Industry, Deceptive Advertisement

\section{Introduction}

Nowadays deceptive advertising has become one of the most highly discussed and major concern in the world. It is now more than a regular practice in any industry. Businesses are going far from the ethical issues. Most of the marketers' only focus is to make money. And advertising has played a major role in the business world to reach the customers more 
effectively and efficiently. Typically, advertising is considered as one of the most important and powerful promotional tools in today's competitive world to create demand for the products. People can gather the information about the quality products and the ingredients from the advertisements. Advertising also helps the company to increase awareness and influence the consumers' perception. But the multinational, global and local companies' use deceptive advertising to sell their products which has direct effects on consumer's buying behavior. They use false, misleading and colored information about their product's qualities to increase the sales volume. Advertisers publish the misleading, false and fraudulent information through TV, radio, print media, outdoor media, internet and so on. Through these media and false information marketers directly influence the consumers' purchase decision.

Although deceptive advertising is a common phenomenon in every sector but in cosmetics industry it is now an alarming issue. Marketers are using deception in every cosmetics product and consumers' fashion consciousness making them more involved in those products. Person's desire to look good and be highly acceptable in society influences them to buy more cosmetics products and that's why the Cosmetics industry of Bangladesh is growing day by day. Moreover, consumers are bombarded with tons of advertisements that make them motivated to buy the cosmetics products.

Both the men and women buy cosmetics products and respond to various advertisements in different way. But women feminine attitudes regarding beautifications and physical attractiveness makes them to purchase more beautifications and skin care products. Women represent $70-80 \%$ percent of the whole consumer purchasing and according to Global Professional Services Firm EY the global income of women are predicted to reach $\$ 18$ trillion in 2018 (Bridget Brennan 2015). So, Women are the most powerful consumers and the most valuable target market for the cosmetics industry. Advertisers, by giving false information and by trying fraudulent affect the consumers and violate the efficient functioning system of the market. The trend of using deception in advertising has been increasing in Bangladesh since 2000. But nowadays most of the company and advertising agencies in Bangladesh use misguide, colored information, makes exaggerated claims to influence the consumers buying decision. They find it more profitable to target the women for their products. It has now become a crying need to focus on this particular issue and make the consumers specially the women more aware regarding the Deceptive advertising.

\subsection{Objective of the Study}

Primary Objective

The main objective of the study is to identify the impact of deceptive advertising on women buying behavior.

\section{Secondary Objectives}

The specific objectives of the study are-

- To identify the different kinds of deceptive advertising practices marketers, use in Bangladesh. 
- To know the impact in health on women consumer from deceptive advertising.

- To know the impact of social influence from deceptive advertisements on women buying behavior.

- To identify what are the laws exist to protect consumers from deceptive advertising.

- To suggest some recommendations to avoid deceptive advertising.

\section{Literature Review}

Deceptive advertising includes the dishonest information which deceives or is probable to cheat the normal customers to take the buying decision and this misleading marketing is like a profitable practice to the marketers (Official Journal of European Union, 2005). The American Marketing Association (AMA) defines deceptive advertising are those advertising that mislead consumers (1) by making false and fake claims, (2) by not making full disclosure, or (3) by the combination of both ways. According to corson (2010), An advertising will be a deceptive advertising if the company will deceive and proceed it purposefully and intentionally.

Heyman (2010), The Federal Trade Commission (FTC) identified four factors that make an advertisement deceptive. The "reasonable consumer" standard: The ad is deceptive or not that can be defined from "reasonable consumers' point of view who is an average sophisticated and intelligent looks at the ad rather than focusing on certain words. But the FTC tries to find out what is conveyed to the consumer through all elements of an ad. Express vs. implied claims: Express and implied claims that an ad makes is another factor to determine whether the ad is deceptive or not. Implied claims are those that are made indirectly or by inference while the express claims are literally made in the ad.

Misleading by Omission: What an ad does not say is also determined by regulators, if something important misleads consumers and the ad failed to mention.

Materiality: Whether the ad is deceptive or not it is important to determine the claim or omission at issue must be "material" - that is related to consumer's decision to buy or use the product. Performance, price, safety, features and effectiveness of any products are included and related to the material claims. In an article of ethical challenges and customers' rights, the researchers have shown three main orientations in deceptive advertising. First the content of advertising, the process used by marketers to push the advertisement into customers' mind is second and the third one is the methods of tracking individual's special experience over the net to promote companies' products (Maleki \& Pasha, 2012). A study on the criteria and challenges of unethical advertising shown that Billboard, television, radio, newspaper is some of the media to attract customers attention but the social media sites in internet is the latest trend. The inappropriate advertising seen by the children, teenagers, adults and old folks is a major concern. And this inappropriate advertising can bring destructive thoughts to the next generation compared from the past and the present in Malaysia (Bin Nooh et al., 2014).

Most consumers become aware of the product through the advertisements. Consumers' buying behavior can be highly influenced and changed through advertisements. And 
marketers use this opportunity and do the deception to convince the consumer to buy the deceptive products. One of the most popular marketing topics which has been studied and debated over decades and without which no marketing book is completed is The Consumers' buying behavior. The consumer buying process has been described by the predominant approach as Learning, information-processing and decision-making activities which is divided in several sequential steps: Problem identification, Information search, Alternative evaluation, Purchase decision, Post purchase behavior (Dibb et al., 2001; Jobber, 2001; Boyd et al., 2002; Kotler, 2003). Consumers' go through different stages in life. And there are various factors and different situation exit that affect different consumers in every stage of their life.

Massoro (2006) identified factors such as friends, the internet, magazines, social network, siblings, product brand, manufacturing countries, leaflets, newspaper, radio, and beauty parlor/salon that highly influence the students of higher learning institutions. Usman et al. (2010) analyzes how Pakistani people's attitude influenced by the culture. The study indicate that what is the impact on culture on the attitude of people towards advertisements according to product information, social integration and pleasure, whereas power distance and masculinity as culture dimension. A lot of individual changes have been determined in an investigation about consumers' responsiveness to advertising and deceptive claims. Through the Types of individuals' characteristics; dispositional and developmental are the major types (Xie and Boush 2011). The programmed features such as the age, gender, family and the lifecycle are the Dispositional differences (Barone et al. 2004). John and Cole (1986) claimed Age plays the role of recall and knowledge at the time of processing the advertising information. Moreover, according to Barone et al (2004) gender can also be a factor. According to Xie and Boush (2011) Knowledge and expertise are the developmental differences that can change with time. The knowledge structure of consumer's grows from the perceptual stage (3-7 years), the logical stage (7-11 years), and to the reflective stage (11-16 years) (John 1999). Both the individuals' characteristics and situational context can affect the salience of the advertisements (Xie \& Boush, 2011). (Fauzia, Ali, Syed Usman, Muhammad Shoaib, Waqas, Muhammad Adnan, Aamir, 2011) have explored that university students increased their use of beauty products because of the deceptive advertising of beauty products. This study selected 142 respondents from Pakistan as its sample size and tested multiple factors by using correlation and regression method. The result of the study showed that there is a strong positive correlation between deceptive advertising and students' buying behavior of beauty products. And the researcher suggested to the marketers and government body to impose such laws against deceptive advertising of beauty products. A study has emphasized that advertisers make false claimed ads to the college students and they get quickly attracted toward those beauty products. The study focused on a sample of 2108 respondents from India and tested multiple factors by using chi-square and ANOVA test. The findings of study showed that spending and buying behavior of students do not influenced by advertisements and students' attitude \& purchasing behavior are positive (Dr. Juao 2014).

Both men and women respond differently to different advertisements. But it is considered that women respond more to any advertisements and purchase decision than men. According 
to Dionne, Davis, Fox and Gurevich (1995) Body satisfaction significantly related to the women's physical attractiveness but it does not define the overall feminine attitude. The cosmetics industry related to the production of beautification products should not contradict the real feminine issues in the bid to exploit them. The rate of ad exposure and consumption is far greater for women than men (Cohan, 2001). The advertising effect is mostly increased by the female beauty endorsers (Lin \& Yeh, 2009).

Marketers are using deceptive advertising for their own sake and they don't think about the future results. But these deceptive advertisements have serious impact on our health and society. (Sing \& Sandhu 2011) The commercials are moving in a direction that has huge social tension and to which solutions are still not found. The commercials are transferring power to the businesses that have consistently ignored social implications of their actions. (Sujata and Bhawna 2012) have shown that television commercials are playing a vital role to influence the buyers specially the teenagers and young. They are influenced by these commercials to such an extent that they believe that these commercials will provide same prestige, satisfaction and happiness. The side effects like dandruff, skin irritation, hair loss, allergic reaction, thinning eyelashes, skin cancer, aging and wrinkling of skin are mostly associated with the use of cosmetics products (Massoro, 2006). Yet, according to the report cosmetics and beautification products are highly selling products (The Weekend Leader, 2009).

Deceptive advertising has lots of major consequences so the government should take proper initiatives for consumer's rights. Liepinyte and Daugeliene (2012) shown the interrelation of deceptive advertising and solution for consumers' as the legal regulations and institutional background in Lituania. In a qualitative research in Europe researchers found that purchasing decision of consumer's is ended up through deceptive practices in advertisements at high prices and low quality. For this reason, they have emphasized on fair and decent advertisements. After the study, European Union introduced laws and regulations to protect the consumers from misleading advertisements, and also to protect them from misleading advertisements, they ensured proper education and awareness for consumers (Monika \& Rasa 2012).

Deceptive advertisement is a crucial issue. It may be a profitable way for marketers but the impact of deceptive marketing is very alarming on consumers. There has been a lot of research on the impact of deceptive advertisements on consumers related to the cosmetics industry around the world but in Bangladesh there are very few researches on this topic. So, this research will particularly focus on the impact of deceptive advertising on women buying behaviour towards cosmetics industry.

\section{Methodology}

The study is basically quantitative study. It is descriptive in nature but based on quantitative information. For this study, the author has chosen cosmetics industry which is largely engaged in deceptive advertising. Both primary and secondary data are used for the study.

Primary data and information are collected through a structured questionnaire. Questionnaire 
is designed based on the objectives. Published reports, journals, television advertising, internet, Facebook, newspaper, relevant articles, etc. are used to collect secondary data. The structured questionnaire is circulated through mail to find out the impact of deceptive advertising on women buying behavior. In the questionnaire, some statements and factors about deceptive advertising are presented for measuring the extent they agreed or disagreed through using a five-point 'Likert Scale' with descriptive anchors ranging from (1) 'Strongly disagree' to (5) 'Strongly agree'.

\subsection{Sampling}

Women are the target sample for the study. To conduct the research, convenience sampling is used. Accepting $\mathrm{e}=6.50 \%$ error, confidence level $\mathrm{z}=95 \%, \mathrm{p}=.50$ and $\mathrm{q}=.50$ the sample size has been determined as follows:

$$
\text { Sample size } \mathrm{n}=1.962 *(.5 * .5) / .65^{2}=227 \text { (Source: Malhotra, N.K 2007) }
$$

227 respondents from diversified occupational background are selected. These respondents are from the age of 20-40 years. Most of the respondents are the university students and the working women. Basic statistical tools like Descriptive Statistics, Factor analysis and Regression model with the help of SPSS are used in this study to analyze the primary data.

\section{Data Analysis and Findings}

\subsection{Descriptive Analysis}

Descriptive statistics are used to describe the basic features of the data in a study. They provide simple summaries about the sample and the measures.

Table 1. Descriptive Analysis

\begin{tabular}{|c|c|c|c|c|c|c|c|c|}
\hline & $\begin{array}{l}\text { My } \\
\text { lifestyle } \\
\text { affects my } \\
\text { buying } \\
\text { decision } \\
\text { on } \\
\text { cosmetics } \\
\text { products }\end{array}$ & $\begin{array}{l}\text { I like to buy } \\
\text { the } \\
\text { cosmetics } \\
\text { products } \\
\text { which refer } \\
\text { to my socia } \\
\text { class. }\end{array}$ & $\begin{array}{l}\text { yStereotype } \\
\text { role in } \\
\text { advertising } \\
\text { influence } \\
\text { sme to buy } \\
\text { lcosmetics } \\
\text { products. }\end{array}$ & $\begin{array}{l}\text { I like to } \\
\text { buy } \\
\text { cosmetics } \\
\text { products } \\
\text { which my } \\
\text { role } \\
\text { models } \\
\text { use. }\end{array}$ & $\begin{array}{l}{ }^{0} \text { Heavy use } \\
\text { of } \\
\text { cosmetics } \\
\text { products } \\
\text { has severa } \\
\text { side } \\
\text { effects. }\end{array}$ & $\begin{array}{l}\text { Cosmetics } \\
\text { products } \\
\text { fail to giv } \\
\text { lpromised } \\
\text { services. }\end{array}$ & $\begin{array}{l}\text { Cosmetic } \\
\text { s produc } \\
\text { emanage } \\
\text { my healt } \\
\text { care. }\end{array}$ & $\begin{array}{l}\text { I am } \\
\text { unaware of } \\
\text { sthe } \\
\text { consequen } \\
\text { hces of the } \\
\text { cosmetics } \\
\text { products. }\end{array}$ \\
\hline Valid & 227 & 227 & 227 & 227 & 227 & 227 & 227 & 227 \\
\hline Missing & 0 & 0 & 0 & 0 & 0 & 0 & 0 & 0 \\
\hline Mean & 3.8062 & 3.6520 & 3.2203 & 2.6123 & 4.1762 & & & \\
\hline Median & 4.0000 & 4.0000 & 3.0000 & 2.0000 & 5.0000 & 4.0000 & 3.0000 & 2.0000 \\
\hline Mode & 4.00 & 4.00 & 3.00 & 2.00 & 5.00 & 4.00 & 3.00 & 1.00 \\
\hline $\begin{array}{l}\text { Std. } \\
\text { Deviation }\end{array}$ & 1.10804 & .93484 & 5.00044 & 1.32017 & 1.14241 & 1.01716 & .94979 & 1.15241 \\
\hline
\end{tabular}

The table shows the descriptive statistics of social and health variables. It shows the mean, median and the mode score of those variables. Here, the highest mean score, which is 4.1762 and it is far above the neutral mean score of, and it indicates that the majority of the 
respondent strongly agreed with the statement that heavy use of cosmetics products have several side effects. Women have faced or they believe that heavy use of cosmetics products can cause several health problems. Some women who have faced minimum health problems were found to have stopped using those cosmetics products. The mean value of whether lifestyle affect the purchase decision of cosmetics product is 3.8062 , which indicates that women prefer to buy those particular cosmetics products that reflect their lifestyle. They try to always purchase those beautification products which maintains their standard. The mean value 3.6520 says that women also prefer to buy those cosmetics products that refers to their social class. Advertisements of the beautification products that can give social approval are acceptable to them. The mean value of whether stereotype role in advertising influence women consumer to buy is 3.2203. Women consumers' agreed with the statement that they got influenced by the stereotype role in advertisements. More than an average of the women agree that cosmetics products use stereotyped role of women in their advertisements. Those advertisements shows that women should focus on beautifying themselves, and if they use those products, they can place themselves in the matrimonial market and can get smart and well-established husband, also it shows that by using those products they can become more self-confident. Mean value of following a role model is 2.6123 , which indicates that women don't get influenced by their role model in buying the cosmetics products. Less than an average of the respondents agrees that seeing the model on screen during commercial advertisements causes them to visualize themselves becoming like those models. We can say that celebrities can draw consumers' attention through advertisements; but the users or the consumers are responsible for purchasing the product. Most women search for the product's information and if the information is satisfying or appears to be truthful then they take the positive approach of buying the cosmetics products. Cosmetics industry has now created a platform through clever and misleading advertising that provide amazing solutions to unbelievable and unpleasant situations. Maximum women consumers agree that deceptive advertising creates misperception that directly impacts on women consumers' social thinking and social conscience. Mean value 3.4361 says that women know that cosmetics products can't fulfill the fake promises that they do through deceptive advertisements. Less than an average respondent agree that cosmetics products can manage their health care. Mean value 2.6740 says women prefer visiting the doctor rather than depending on cosmetics products in case of managing their own health care. The mean value of being unaware of the consequences of cosmetics products is 2.2643 , which indicates that women are aware about the cosmetics products after-use negative consequences. They are very much concern at the time of purchasing any cosmetics products.

\subsection{Factor Analysis}

Factor analysis is used to describe variability among observed, correlated variables in terms of a potentially lower number of unobserved variable or factors. 
Table 2. Factor Analysis

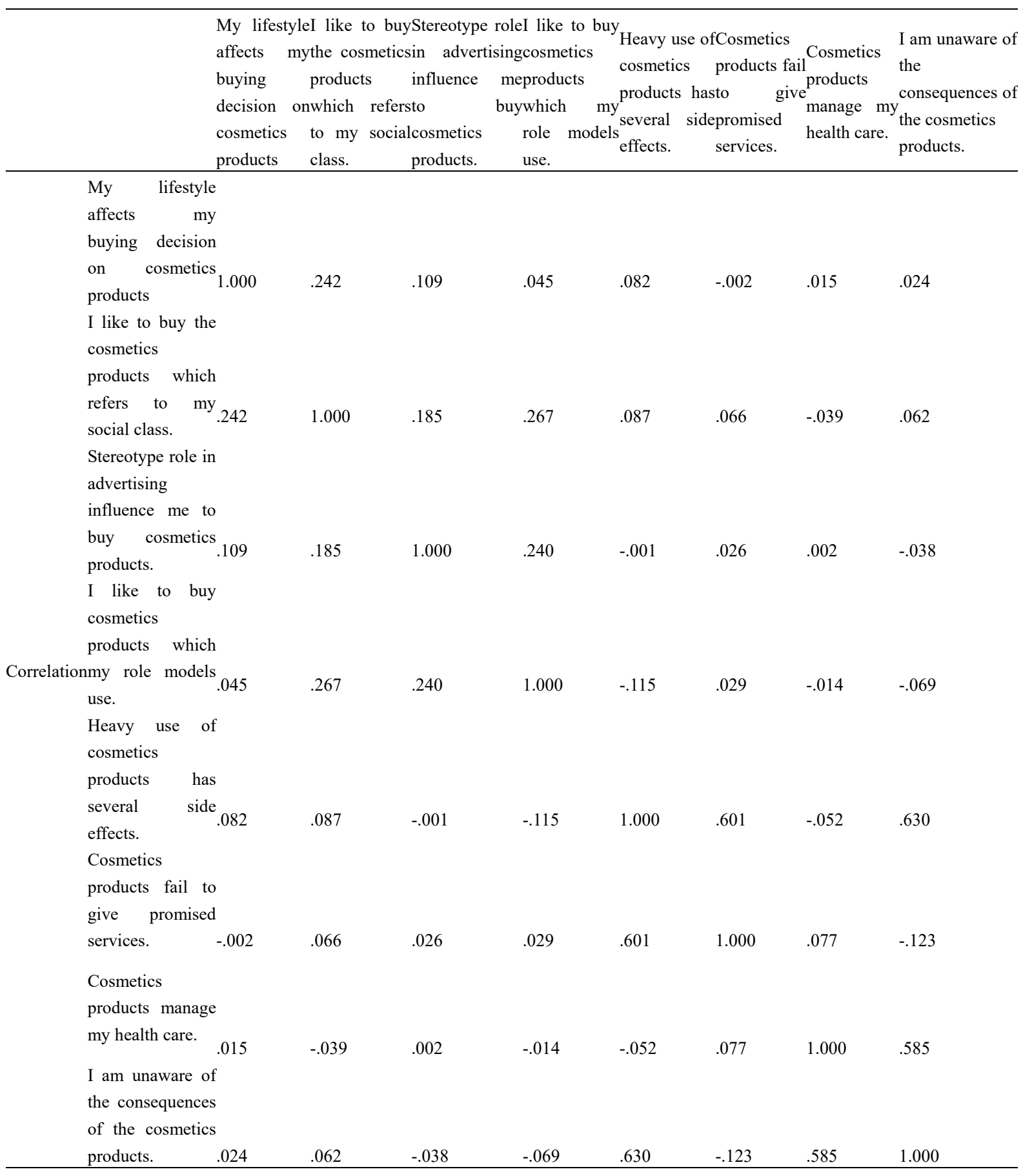

This table is the correlation matrix of both health impact and social impact variables that showing how each of the 8 items are associated with each of the other 7. In the table variables have both positive and negative correlation and most of the variables have high correlation that indicates they will not have high loadings on the same factor. The determinant should be more than .0001 and here, the determinant is .829 , which means multicollinearity is not a problem and all the questions are fairly correlated. 


\subsection{KMO and Bartlett's Test}

Table 3. KMO and Bartlett's Test

\begin{tabular}{lll}
\hline Kaiser-Meyer-Olkin Measure of Sampling Adequacy. & .786 \\
\hline \multirow{3}{*}{ Bartlett's Test of Sphericity } & Approx. Chi-Square & 70.221 \\
& Df & 28 \\
& Sig. & .000 \\
\hline
\end{tabular}

The Kaiser-Meyer-Olkin (KMO) measure should be greater than .70 and is inadequate if less than .50. Here it is .786 so that is good. And the value is close to 1 so we can say that patterns of correlations are relatively compact and so factor analysis should yield distinct and reliable factors. The Bartlett test should be significant (i.e., a significance value of less than .05); this means that the variables are correlated highly enough to provide a reasonable basis for factor analysis. Here the test is highly significant and therefore R-matrix is not an identity matrix and we can reject both the null hypothesis.

\subsection{Total Variance Model}

Table 4. Total Variance Model

\begin{tabular}{|c|c|c|c|c|c|c|}
\hline & Initial Eigenv & & $\begin{array}{l}\text { Extraction } \mathrm{Su} \\
\text { Loadings }\end{array}$ & f Squared & $\begin{array}{l}\text { Rotation Sum } \\
\text { Loadings }\end{array}$ & Squared \\
\hline Componen & Total $\%$ of Va & $\begin{array}{l}\text { Cumulat } \\
\mathrm{e}_{\%}\end{array}$ & Total $\%$ of Va & $\begin{array}{l}\text { Cumulat } \\
\mathrm{e}_{\%}\end{array}$ & Total $\%$ of $\mathrm{Va}$ & $\mathrm{e}_{\%}^{\text {Cumula }}$ \\
\hline 1 & 1.57019 .620 & 19.620 & 1.57019 .620 & 19.620 & 1.45818 .226 & 18.226 \\
\hline 2 & 1.17914 .737 & 34.357 & 1.17914 .737 & 34.357 & 1.28316 .041 & 34.267 \\
\hline 3 & 1.13814 .223 & 48.580 & 1.13814 .223 & 48.580 & 1.13914 .236 & 48.503 \\
\hline 4 & 1.06513 .309 & 61.889 & 1.06513 .309 & 61.889 & 1.07113 .386 & 61.889 \\
\hline 5 & .87910 .987 & 72.877 & & & & \\
\hline 6 & .82810 .350 & 83.227 & & & & \\
\hline 7 & .7279 .088 & 92.315 & & & & \\
\hline 8 & .6157 .685 & 100.000 & & & & \\
\hline
\end{tabular}

The Total Variance Explained table shows how the variance is divided among the 8 possible factors. Here factor 1 explain $19.620 \%$ variance of total variance. The first three factors explain relatively large amount of variance (especially factor 1) whereas the last two factors explain small amount of variance. SPSS extracts all factors with eigenvalues greater than 1, which leaves us with four factors. The eigenvalues associated with these factors are again displayed in the columns labelled Extraction Sums of Squared Loadings. The values in the part of the table are the same as the values before extraction. In the final part of the table labelled Rotation Sums of Squared Loadings, the eigenvalues of the factors after rotation are displayed. Before rotation, factor 1 accounted for considerably more variance than the remaining factors $(19.620 \%$ compared to $14.737,14.223,13.309,9.088,7.685 \%)$, however after extraction it accounts for $18.226 \%$ of variance compared to $(16.041,14.263,13.386 \%$ respectively). 


\subsection{Regression Model}

Regression model is used to understand which among the independent variables are related to the dependent variable, and to explore the forms of these relationship.

Table 5. Regression Model

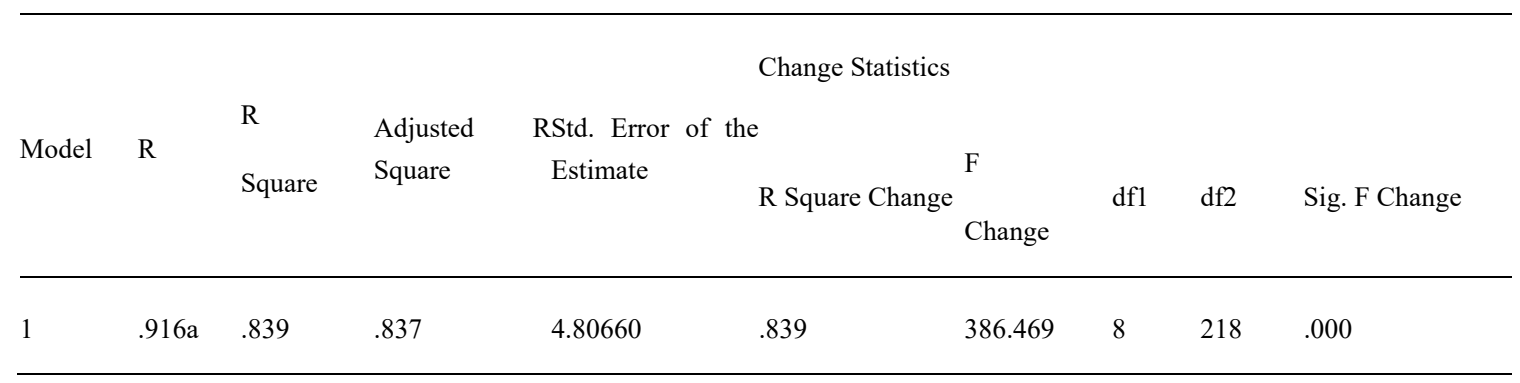

Purchase behavior of cosmetics products is strongly dependent on the mentioned predictors signifying the impact of deceptive advertisement with the variables. In the cosmetics industry $83.9 \%$ of the variation in the dependent variable is explained by the independent variables of the model. The other $16.1 \%$ variation in the dependent variable remains unexplained by the independent variables of the study. R-square is the coefficient of multiple determinations. It describes how big part of the dependent variable is explained by the set of independent variables selected in the regression equation ( 0.0 or $0 \%$ is low and 1.0 or $100 \%$ is high). Here adjusted $\mathrm{R}$-square is reported. It is a modification of $\mathrm{R}$ - square that adjusts for the number of terms in a model. R-square increases when a new term is added to a model, whereas adjusted R-square increases only if the new term improves the model more than would be expected by chance. Adjusted R-square is generally considered to be a more accurate goodness of-fit measure than R-square. In the regression analysis, cosmetics industry there is little decrease in adjusted R-square as some variables have been removed from the model. When explaining the impact of deceptive advertisement, we can see that reduction of the chosen variables does not have any significant impact on the purchase behavior of cosmetics products.

Hypothesis Testing: The $p$ value in every analysis shows that the variables are statistically significant and they are highly correlated with each other so both the null hypothesis that there is no impact in health of women and there is no impact of social influence on women buying behavior are automatically rejected and the alternative hypothesis are accepted.

Finally, from the above analysis, it can be concluded that the impact of deceptive advertising on women buying behavior is highly significant and related to the other variables.

\section{Conclusions}

It is clear that there exist a lot of deceptive advertisements of cosmetics products in Bangladesh. And also, on the basis of the above analysis and findings, it can be concluded that in our country the current system of legal protection to the consumers from deceptive 
advertisements is quite inadequate and outdated. Moreover, from the survey, it has shown that women get influenced by their lifestyle and social class in purchasing cosmetics products. They always like to verify what the products promised to offer. But most of the time the cosmetics products fail to keep what they promise, which then results in deceptive advertisements. Thus, deceptive advertisements give some misrepresentations to women. And that's why to secure and maintain the lifestyle and social status most of the women don't hesitate to pay more for those cosmetics products. The proper implementation of advertising rules and regulations and also the consumer protection laws can be the solution to this trend. Moreover, different workshops, seminars can make women more knowledgeable about these deceptive advertising. Companies can encourage their creative team to avoid those ideas that show women as kits. Awareness can also be created through social networking site as it has now become a powerful platform for showing any kind of information. So, women can use the platform for articulating the side effects of the cosmetics products and their fake claims. Women consumers should be protected from these deceptive practices and they should be kept safe from the negative impact of those cosmetics products by making the "consumer rights protection act" more efficient and effective.

\section{References}

Bettman, J. R. (1979), An Information-Processing Theory of Consumer Choice, Addison-Wesley, Glen View, IL.

Brassington, F., \& Pettitt, S. (2003). Principles of Marketing, 3rd ed., Prentice-Hall/Financial Times, Englewood Cliffs, NJ.

Cohan, J. A. (2001). Towards a new paradigm in the ethics of women's advertising. Journal of Business Ethics, 33(4), 323-337. https://doi.org/10.1023/A:1011862332426

Consumer Rights Protection Act. (2009). Act no 26 of 2009, The Directorate of National Consumers' Right Protection (DNCRP).

Dionne, M., Davis, C., Fox, J., \& Gurevich, M. (1995). Feminist ideology as a predictor of body dissatisfaction in women. Sex Roles, 33(3), 277-287. https://doi.org/10.1007/BF01544615

Fauzia, A. S. (2011). Attraction of Students Towards Beauty Products. Australian Journal of Business and Management Research, 104-108. https://doi.org/10.52283/NSWRCA.AJBMR.20110103A010

Jobber, D. (2001). Principles \& Practice of Marketing. McGraw-Hill International (UK) Limited, New York, NY.

Kotler, P. (2003). Marketing Management (11th ed.). Prentice-Hall International Editions, Englewood Cliffs, NJ.

Maleki \& Pasha (2012). Three main orientation of deceptive advertising. "Ethical challenges and consumers' rights".

Rasa Daugeliene, M. L. (2012). Interrelation of misleading advertising and solutions of 


\section{Macrothink}

consumers. European Integration Studies.

Zainabu Zuberi Massoro. (2006). Information Seeking and Use Behaviour on Beautification Product among Students of Higher Learning Institutions.

\section{Copyrights}

Copyright for this article is retained by the author(s), with first publication rights granted to the journal.

This is an open-access article distributed under the terms and conditions of the Creative Commons Attribution license (http://creativecommons.org/licenses/by/4.0/) 